\title{
Differentiated Thyroid Gland Carcinoma by AJCC v7 Stage
}

National Cancer Institute

\section{Source}

National Cancer Institute. Differentiated Thyroid Gland Carcinoma by A/CC v7 Stage. NCI Thesaurus. Code C140959.

A term that refers to the staging of differentiated thyroid gland carcinoma, following the rules of the TNM AJCC V7 classification system. 